\title{
Response to Swinnen et al.
}

\section{Dear Editor:}

Interpretation of data from the comparison of two insulins in a clinical trial setting is challenging when the insulins are studied in different dosing regimens and their titration is performed using different algorithms. In a recent article, Swinnen et al. ${ }^{1}$ attempt to justify their design of L2T3, namely, the comparison of twice-daily detemir to once-daily glargine. However, differences in dosing regimens and the complexity of titration algorithms have the potential to impact all aspects of the results, including efficacy, safety, and patient-reported outcomes. Caution should be exercised when designing such a study, and even more caution should be exercised when interpreting the results.

Swinnen et al. acknowledge that the benefits of insulin glargine and insulin detemir compared to those of neutral protamine Hagedorn (NPH) insulin had been established at the time the L2T3 study was designed. ${ }^{2-4}$ However, the authors questioned the efficacy of detemir in a once-daily regimen based on the results of one regulatory submission study ${ }^{5}$ and one other study, by Hermansen et al., ${ }^{2}$ that evaluated detemir and NPH in twice-daily dosing regimens. While the regulatory submission study did demonstrate a greater decrease in hemoglobin $\mathrm{A} 1 \mathrm{c}(\mathrm{HbA} 1 \mathrm{c})$ with $\mathrm{NPH}$ and a similar decrease in fasting plasma glucose, less weight gain, and a lower risk of minor and nocturnal hypoglycemia with detemir, Hermansen et al. ${ }^{2}$ showed similar efficacy and confirmed less weight gain and a lower risk of overall and nocturnal hypoglycemia with detemir. It is important to consider several other published studies supporting the once-daily use of detemir, including pharmacokinetic/pharmacodynamic studies $^{6,7}$ and randomized clinical trials in type 1 and type 2 diabetes. $^{8-10}$ The labeling for detemir allowed for once- or twice-daily dosing at the time of the design of the study. It is regrettable that Swinnen et al. did not include a third arm in order to compare insulin glargine (once daily) to insulin detemir (once and twice daily).

Swinnen et al. further reference a study of once-daily detemir versus once-daily NPH by Philis-Tsimikas et al. ${ }^{11}$ and, despite the similar efficacy observed in this study, raise doubts as to "whether such a strategy will help as many people achieve good control as NPH or glargine once daily." They highlight final $\mathrm{HbA1c}$ values of $7.4 \%$ for both detemir and NPH as a concern. In fact, the overall changes in HbA1c from beginning to end of the study and the insulin doses used at the end of the study were similar to those observed in Riddle et al., ${ }^{3}$ and Philis-Tsimikas et al. ${ }^{11}$ used a less aggressive insulin titration schedule. It is important to note that four separate studies with insulin glargine demonstrated comparable end points, with final $\mathrm{HbA} 1 \mathrm{c}$ values above $7 \%{ }^{12-15}$
Swinnen et al. also reference studies in which patients using detemir "required" a second daily injection ${ }^{16,17}$ but do not explain the study designs in these investigations. Rosenstock et al. ${ }^{16}$ required only patients using detemir-not those using glargine, because of labeling restrictions - to add a second daily dose if prespecified, pre-dinner titration targets were not achieved. In fact, a post hoc evaluation of this study indicated that a similar percentage of glargine patients would have required twice-daily dosing if the same titration schedule was applied to those patients using glargine. ${ }^{18}$ However, it cannot be known if patients injecting insulin glargine twice daily would have experienced the same effect on blood glucose as those patients injecting insulin detemir twice daily. A subanalysis of the $45 \%$ of patients who remained on once-daily insulin detemir in this study demonstrated equivalent efficacy, safety, and dosing between detemir and glargine and spurred the design of future trials that have studied detemir exclusively in a once-daily regimen in patients with type 2 diabetes taking oral antidiabetes drugs. ${ }^{11,19}$

While Swinnen et al. attempt to justify the rationale behind the twice-daily dosing regimen for detemir in L2T3, a discussion of what has been learned since the design of the study was not provided. Specifically, the authors make no mention of the numerous studies supporting the once-daily use of detemir, including randomized controlled trials and large observational studies $^{11,16,19-24}$ and clamp and continuous glucose monitoring studies demonstrating comparable timeaction profiles between detemir and glargine. ${ }^{25,26}$ In fact, according to the 2009 American Association of Clinical Endocrinologists/American College of Endocrinology guidelines, "detemir can be used with 1 injection per day in patients with type 2 diabetes; excellent reproducibility of absorption profile within individuals; possibly less weight gain than with other insulins." ${ }^{27}$ Current labeling for detemir in the countries participating in L2T3, including Europe, Canada, and Australia, ${ }^{28-30}$ recommends the use of detemir once daily in combination with oral antidiabetes drugs for the treatment of type 2 diabetes. While an exhaustive discussion of more recent data cannot be expected, some reference to current literature should have been provided, as it is important to acknowledge what has been learned since the design of L2T3 in order to place its design and anticipated results into perspective.

Finally, although it has previously been demonstrated in patients with type 1 diabetes prior to the design of L2T3, ${ }^{31}$ Swinnen et al. also fail to acknowledge the now wellestablished concept that twice-daily dosing regimens of any basal insulin elevate the dose compared to once-daily regimens, with limited additional impact on glycemic control. ${ }^{16,32}$ The addition of a second basal dose also is likely to adversely 
impact hypoglycemia rates, weight gain, the prevalence of injection site reactions, and overall quality of life, including treatment satisfaction. ${ }^{31}$ This learning is important to share when discussing the design of L2T3 to ensure the results are discussed in proper perspective.

In summary, only one study has evaluated insulin detemir and insulin glargine in a head-to-head comparison as an addon to oral therapy in type 2 diabetes. ${ }^{16}$ The L2T3 study will contribute to the literature concerning the treatment of type 2 diabetes with basal insulin; however, any differences between insulin detemir and insulin glargine would have been more clearly identified had the analogs been studied in identical dosing regimens. It is reasonable to assume that any observed differences in outcomes between the two analogs in the L2T3 study may be a result of the different dosing regimens, especially with respect to dosage, hypoglycemia, and patientreported outcomes, as well as the inherent differences between the analogs. The results from the L2T3 study, together with those from an ongoing study comparing insulin detemir and insulin glargine in identical, once-daily dosing regimens (the Effect of Insulin Determir and Insulin Glargine on Blood Glucose Control in Subjects with Type 2 Diabetes [EFFICACY ${ }^{\mathrm{TM}}$ ] trial [identified as NCT00909480 at http:// www.clinicaltrials.gov]), will provide valuable information about the use of these analogs in the treatment of type 2 diabetes and will benefit the diabetes community.

\section{Acknowledgments}

The authors wish to thank Rebecca Shaffer, Ph.D., of Novo Nordisk Inc. and Lisa Sullivan of Watermeadow Medical USA for editorial assistance in preparing this letter for publication. Funding for editorial assistance was provided by Novo Nordisk Inc.

\section{Author Disclosure Statement}

A.C.M. and C.K. are employees of and shareholders in Novo Nordisk.

\section{References}

1. Swinnen SGHA, Snoek FJ, Dain M-P, DeVries JH, Hoekstra JBL, Holleman F: Rationale, design, and baseline data of the insulin glargine (Lantus) versus insulin detemir (Levemir) Treat-to-Target (L2T3) study: a multinational, randomized noninferiority trial of basal insulin initiation in type 2 diabetes. Diabetes Technol Ther 2009;11:739-743.

2. Hermansen K, Davies M, Derezinski T, Martinez Ravn G, Clauson P, Home P: A 26-week, randomized, parallel, treatto-target trial comparing insulin detemir with $\mathrm{NPH}$ insulin as add-on therapy to oral glucose-lowering drugs in insulin naïve people with type 2 diabetes. Diabetes Care 2006; 29:1269-1274. Erratum in: Diabetes Care 2007;30:1035.

3. Riddle MC, Rosenstock J, Gerich J; Insulin Glargine 4002 Study Investigators: The treat-to-target trial: randomized addition of glargine or human NPH insulin to oral therapy of type 2 diabetic patients. Diabetes Care 2003;26:3080-3086.

4. Horvath K, Jeitler K, Berghold A, Ebrahim SH, Gratzer TW, Plank J, Kaiser T, Pieber TR, Siebenhofer A: Long-acting insulin analogues versus NPH insulin (human isophane insulin) for type 2 diabetes mellitus. Cochrane Database Syst Rev 2007;(2):CD005613.
5. European Medicine Agency: Levemir European Public Assessment Report. Revision 10, 22 July 2008. http://www. emea.europa.eu/humandocs/Humans/EPAR/levemir/levemir. htm (accessed December 11, 2009).

6. Heise T, Nosek L, Rønn BB, Endahl L, Heinemann L, Kapitza C, Draeger E: Lower within-subject variability of insulin detemir in comparison to NPH insulin and insulin glargine in subjects with type 1 diabetes. Diabetes 2004; 53:1614-1620.

7. Plank J, Bodenlenz M, Sinner F, Magnes C, Gorzer E, Regittnig W, Endahl LA, Draeger E, Zdravkovic M, Pieber TR: A double-blind, randomized, dose-response study investigating the pharmacodynamic and pharmacokinetic properties of the long-acting insulin analog detemir. Diabetes Care 2005;28:1107-1112.

8. Russell-Jones D, Simpson R, Hylleberg B, Draeger E, Bolinder J: Effects of QD insulin detemir or neutral protamine Hagedorn on blood glucose control in patients with type I diabetes mellitus using a basal-bolus regimen. Clin Ther 2004;26:724-736.

9. Haak T, Tiengo A, Draeger E, Suntum M, Waldhäusl W: Lower within-subject variability of fasting blood glucose and reduced weight gain with insulin detemir compared to $\mathrm{NPH}$ insulin in patients with type 2 diabetes. Diabetes Obes Metab 2005;7:56-64.

10. Raslová K, Bogoev M, Raz I, Leth G, Gall MA, Hâncu N: Insulin detemir and insulin aspart: a promising basal-bolus regimen for type 2 diabetes. Diabetes Res Clin Pract 2004;66:193-201. Erratum in: Diabetes Res Clin Pract 2006;72:112.

11. Philis-Tsimikas A, Charpentier G, Clauson $P$, Martinez Ravn G, Roberts VL, Thorsteinsson B: Comparison of once-daily insulin detemir with NPH insulin added to a regimen of oral antidiabetic drugs in poorly controlled type 2 diabetes. Clin Ther 2006;28:1569-1581.

12. Fritsche A, Schweitzer MA, Häring HU; 4001 Study Group: Glimepiride combined with morning insulin glargine, bedtime neutral protamine hagedorn insulin, or bedtime insulin glargine in patients with type 2 diabetes. A randomized, controlled trial. Ann Intern Med 2003;138:952-959.

13. Kennedy L, Herman WH, Strange P, Harris A; GOAL A1C Team: Impact of active versus usual algorithmic titration of basal insulin and point-of-care versus laboratory measurement of $\mathrm{HbA} 1 \mathrm{c}$ on glycemic control in patients with type 2 diabetes: the Glycemic Optimization with Algorithms and Labs at Point of Care (GOAL A1C) trial. Diabetes Care 2006;29:1-8.

14. Davies M, Storms F, Shutler S, Bianchi-Biscay M, Gomis R; ATLANTUS Study Group: Improvement of glycemic control in subjects with poorly controlled type 2 diabetes: comparison of two treatment algorithms using insulin glargine. Diabetes Care 2005;28:1282-1288.

15. Standl E, Maxeiner S, Raptis S; HOE901/4009 Study Group: Once-daily insulin glargine administration in the morning compared to bedtime in combination with morning glimepiride in patients with type 2 diabetes: an assessment of treatment flexibility. Horm Metab Res 2006;38:172-177.

16. Rosenstock J, Davies M, Home PD, Larsen J, Koenen C, Shernthaner G: A randomised, 52-week, treat-to-target trial comparing insulin detemir with insulin glargine when added to glucose-lowering drugs in insulin-naive people with type 2 diabetes. Diabetologia 2008;51:408-416.

17. Holman RR, Thorne KI, Farmer AJ, Davies MJ, Keenan JF, Paul S, Levy JC; 4-T Study Group: Addition of biphasic, 
prandial, or basal insulin to oral therapy in type 2 diabetes. N Engl J Med 2007;357:1716-1730.

18. Koenen C: How do detemir and glargine compare when added to oral agents in insulin-naïve patients with type 2 diabetes mellitus? Nat Clin Pract Endocrinol Metab 2008;4:E1.

19. Blonde L, Merilainen M, Karwe V, Raskin P: Patient-directed titration for achieving glycaemic goals using a once-daily basal insulin analogue: an assessment of two different fasting plasma glucose targets-the TITRATE ${ }^{\mathrm{TM}}$ study. Diabetes Obes Metab 2009;11:623-631.

20. Holman RR, Farmer AJ, Davies MJ, Levy JC, Darbyshire JL, Keenan JF, Paul SK; 4-T Study Group: Three-year efficacy of complex insulin regimens in type 2 diabetes. $\mathrm{N}$ Engl J Med 2009;361:1736-1747.

21. Selam JL, Koenen C, Weng W, Meneghini L: Improving glycemic control with insulin detemir using the 303 Algorithm in insulin naïve patients with type 2 diabetes: a subgroup analysis of the US PREDICTIVE 303 study. Curr Med Res Opin 2008;24:11-20.

22. Dornhorst A, Lüddeke HJ, Koenen C, Merilainen M, King A, Robinson A, Sreenan S; PREDICTIVE Study Group: Transferring to insulin detemir from NPH insulin or insulin glargine in type 2 diabetes patients on basal-only therapy with oral antidiabetic drugs improves glycaemic control and reduces weight gain and risk of hypoglycaemia: 14-week follow-up data from PREDICTIVE. Diabetes Obes Metab 2008;10:75-81.

23. Meneghini LF, Rosenberg KH, Koenen C, Merilainen MJ, Lüddeke HJ: Insulin detemir improves glycaemic control with less hypoglycaemia and no weight gain in patients with type 2 diabetes who were insulin naive or treated with NPH or insulin glargine: clinical practice experience from a German subgroup of the PREDICTIVE study. Diabetes Obes Metab 2007;9:418-427.

24. Yenigun M, Honka M: Switching patients from insulin glargine-based basal-bolus regimens to a once-daily insulin detemir-based basal-bolus regimen: results from a subgroup of the PREDICTIVE ${ }^{\mathrm{TM}}$ study. Int J Clin Pract 2009;63:425-432.

25. King AB: Once-daily insulin detemir is comparable to oncedaily insulin glargine in providing glycaemic control over $24 \mathrm{~h}$ in patients with type 2 diabetes: a double-blind, randomized, crossover study. Diabetes Obes Metab 2009;11:69-71.

26. Klein O, Lynge J, Endahl L, Damholt B, Nosek L, Heise T: Albumin-bound basal insulin analogues (insulin detemir and NN344): comparable time-action profiles but less variability than insulin glargine in type 2 diabetes. Diabetes Obes Metab 2007;9:290-299.

27. Rodbard HW, Jellinger PS, Davidson JA, Einhorn D, Garber AJ, Grunberger G, Handelsman Y, Horton ES, Lebovitz H, Levy P, Moghissi ES, Schwartz SS: Statement by an American Association of Clinical Endocrinologists/American College of Endocrinology consensus panel on type 2 diabetes mellitus: an algorithm for glycemic control. Endocr Pract 2009;15:540-559.

28. European Medicines Agency: European Public Assessment Report (EPAR): Levemir ${ }^{\circledR}$. EPAR summary for the public. http://www.emea.europa.eu/humandocs/PDFs/EPAR/levemir/ H-528-en1.pdf (accessed December 11, 2009).

29. Novo Nordisk Canada Inc.: Product Monograph Part III: Consumer Information: Levemir ${ }^{\circledR}$ (insulin detemir). http:// www. novonordisk.ca/PDF_Files/LevemirPMPatient_En.pdf (accessed December 11, 2009).

30. Novo Nordisk Pharmaceuticals Pty. Ltd.: Levemir ${ }^{\circledR}$ FlexPen ${ }^{\circledR}$ (insulin detemir [rys]): Consumer Medicine Information. http://www.novonordisk.co.nz/LevFpcmi3.pdf (accessed December 11, 2009).

31. Garg SK, Gottlieb PA, Hisatomi ME, D'Souza A, Walker AJ, Izuora KE, Chase $\mathrm{PH}$ : Improved glycemic control without an increase in severe hypoglycemic episodes in intensively treated patients with type 1 diabetes receiving morning, evening, or split dose insulin glargine. Diabetes Res Clin Pract 2004;66:49-56.

32. DeVries H, Pieber T, Nattrass M: Refining basal insulin therapy: what have we learned in the age of analogues? Diabetes Metab Res Rev 2007;23:441-454.

-Alan C. Moses, M.D. Vice President, Global Chief Medical Officer Novo Nordisk Inc. Princeton, NJ

Christoph Koenen, M.D. Corporate Vice President, Medical Affairs Novo Nordisk $A / S$ Hummeltoftevej 49 DK-2830 Virum, Denmark

E-mail: CKOE@novonordisk.com 